\title{
ELECTROCHEMICAL SENSORS FOR MALACHITE GREEN BASED ON CARBONACEOUS NANOMATERIALS
}

\author{
ANA-MARIA SĂCARĂ ${ }^{a}$, LIANA MARIA MUREŞAN ${ }^{\mathrm{a}}$ *
}

\begin{abstract}
Synthetic dyes are widely used in many fields, such as textile industry, plastics, cosmetics, paper industry and many others. Due to their toxicity, they should be removed from wastes before discharging in the environment. In order to determine the efficiency of the removal process, different methods are used to detect traces of dyes in wastewaters. The most used are spectrophotometry and FIA, however the expensive equipment and complicated testing process make these methods difficult to use. On the contrary, electrochemical sensors have multiple advantages such as short response time, low price and easiness to use. In this context, several electrochemical sensors based on new carbonaceous materials were developed and characterized. Carbon nanotubes, graphene and activated carbon from Abies nordmanniana cones together with Nafion were used to modify the surface of a glassy carbon electrode by drop casting. The resulting modified electrodes were tested by SWASV and amperometry for Malachite Green detection in aqueous solutions, having low detection limits in the order of $\mu \mathrm{M}$.
\end{abstract}

Keywords: Malachite Green; electrochemical detection; activated carbon; carbon nanotubes; reduced graphene oxide; modified electrodes.

\section{INTRODUCTION}

The textile industry is one of the most important contributors to water pollution by discharging up to 200,000 tons of wastewaters every year as effluents [1]. Dyes are a large and varied class of compounds with coloring abilities that usually show affinity for the substrate they are applied on, generally in aqueous solution, with or without the use of a mordant for improved fastness [2]. They are widely used in many fields, such as the

\footnotetext{
a Babeş-Bolyai University, Faculty of Chemistry and Chemical Engineering, Department of Chemical Engineering, 11 Arany Janos str., RO-400028,Cluj-Napoca,Romania.

*Corresponding author: limur@chem.ubbcluj.ro
} 
textile industry, plastics, cosmetics, paper industry and many others [3]. Unfortunately, they are usually persistent in the environment [4] and can easily be assimilated in living organisms [5-7]. The dye selected for this study, Malachite Green (MG), exhibits these common characteristics being a potential threat to aquatic life because of its cytotoxic [8], biocidal [9] and bioaccumulation properties [5-7].

Classic detection methods such as HPLC used to detect MG need expensive equipment and a complicated testing process [10]. This is why this study intends to develop new electrochemical sensors designed to accurately and easily determine the concentration of $M G$ from an aqueous solution in a fast and inexpensive way. A new activated carbon (AC) produced from fir (Abies nordmanniana) cones has been utilized for modification of a glassy carbon electrode in order to obtain a very sensitive and selective sensor for MG. The results were compared with those obtained with other nanomaterials such as single-walled carbon nanotubes (SWCNTs) and reduced graphene oxide (RGO) and with those reported in literature [11-14].

The glassy carbon electrodes modified with carbonaceous materials and Nafion presented in this paper were prepared by drop casting and characterized by using square wave anodic stripping voltammetry (SWASV), batch amperometry and electrochemical impedance spectroscopy (EIS).

\section{RESULTS AND DISCUSSION}

\section{Characterization of the carbonaceous materials}

SWCNTs and RGO were commercial products of analytical grade, characterized by the manufacturer.

The artisanal activated carbon prepared in various conditions was characterized by TEM analysis, (Figure 1).

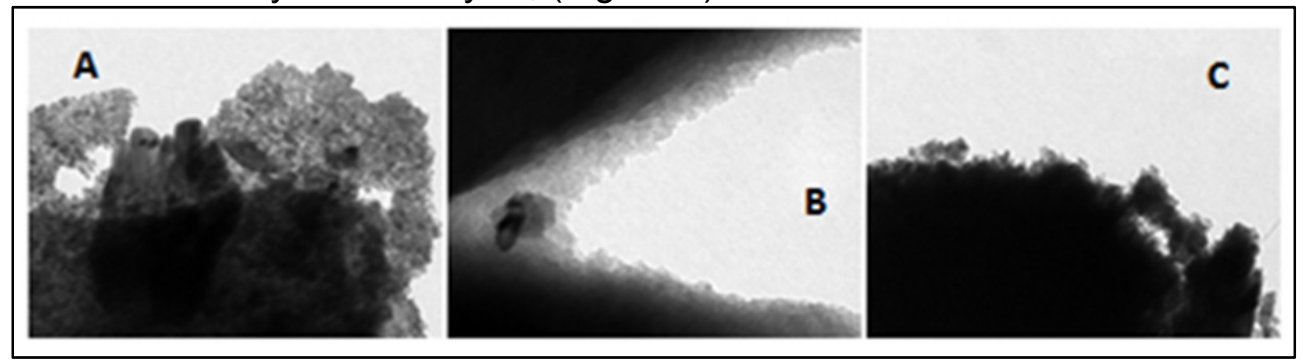

Figure 1. TEM analysis of activated carbon (AC) types, with different concentrations of $\mathrm{NaOH}$ used for chemical activation: $\mathrm{A}-\mathrm{NaOH} 5 \%, \mathrm{~B}-\mathrm{NaOH} 10 \%$ and $\mathrm{C}-\mathrm{NaOH} 20 \%$.

It is observed that the size of the particles can be obviously correlated with the concentration of $\mathrm{NaOH}$ solution in an inverse proportion. The porosity of the material seems to be also affected by $\mathrm{NaOH}$ concentration. 


\section{Square wave anodic stripping voltammetry (SWASV)}

Influence of activated carbon (AC) activation conditions and concentration

Before conducting further experiments with the $A C$, the best nanomaterial had to be chosen among three varieties resulted from various levels of chemical activation with $\mathrm{NaOH}$ solutions of different concentrations. For this purpose, SWASV measurements in MG containing solutions were used at electrodes prepared with the three types of AC.

The anodic oxidation of MG was previously reported and described [14] as taking place with the ejection of an integral unit of the central carbon attached to a phenyl group, intramolecular coupling of two phenyl fragments succeeding this phase, leading to the formation of the oxidized form of $N, N, N^{\prime}, N^{\prime}$-tetramethylbenzidine (TMB), that is 1,1'-biphenyl-4.4'diamine (TMBOX). Thus, the oxidation of MG in acidic aqueous solutions was shown to proceed via an electrochemically irreversible, diffusion controlled, two electron transfer process $[15,16]$.

This process is visible in SWASV measurements where two oxidation peaks occur at approx. $0.4 \mathrm{~V}$ and $0.85 \mathrm{~V}$ vs. $\mathrm{Ag} / \mathrm{AgCl} / \mathrm{KCl}_{\text {sat }}$ (Figures 2A, 4A and $5 \mathrm{~A}$ ). The height of the peaks is proportional to $M G$ concentration, therefore calibration curves were obtained by plotting $I$ as function of MG molar concentration (Figs. 2B, 4B and 5B, for peak II)

In Figure 2 the SWASV curves are illustrated for the variety of $A C$ that gave best results (activated with $\mathrm{NaOH} 5 \%$ ).

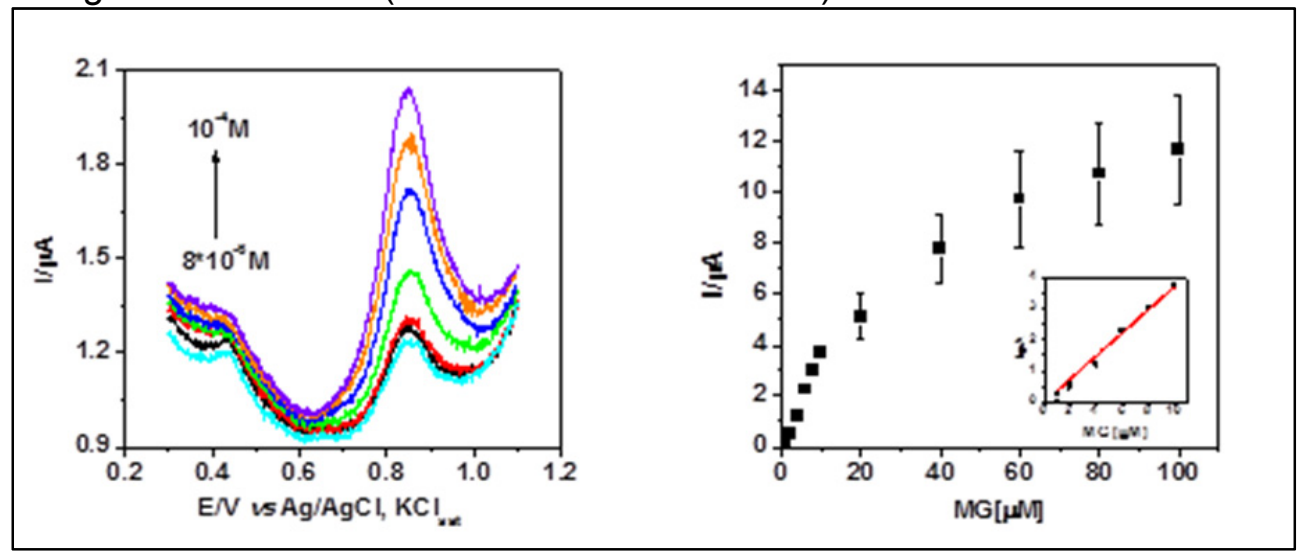

Figure 2. SWASV and calibration curves for GC/AC/Nafion electrodes prepared with $A C$ activated with $\mathrm{NaOH} 5 \%$. Experimental conditions: PB 0.1M, pH 3; $10^{-6}-10^{-4} \mathrm{M}$ MG; frequency, $25 \mathrm{~Hz}$; amplitude, $0.01 \mathrm{~V}$; deposition time, 300s; start potential, $0.3 \mathrm{~V}$ vs. $\mathrm{Ag} / \mathrm{AgCl}, \mathrm{KCl}_{\text {sat. }}$.

Further, the calibration curves for the three tested $A C$ varieties plotted for peak II were compared (Fig 3A). All preliminary experiments were carried 
out in the presence of Nafion coating, for a better stability of the electrodes. Nafion keeps and protects the carbonaceous material on the electrode's surface. Moreover, the possibility of a favorable ionic association between negatively charged Nafion ionomer and cationic MG also exists. These interactions were put in evidence by FT-IR spectra in a previous study [17].

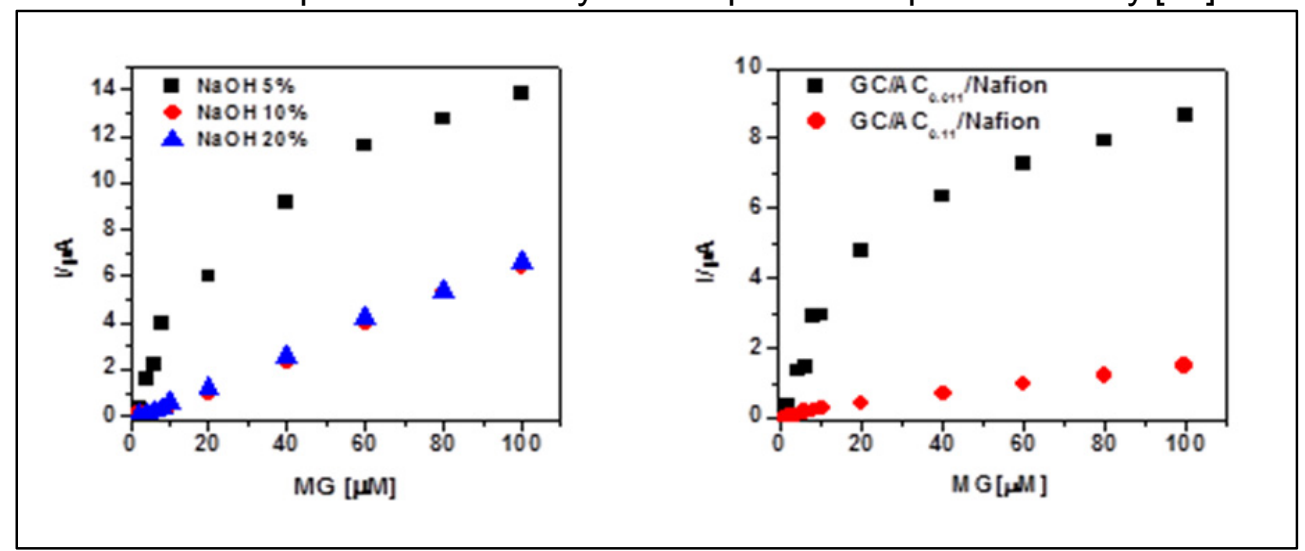

Figure 3. SWASV calibration curves for GC/AC/Nafion electrodes; influence of $\mathrm{NaOH}$ solutions concentration (A) and of $\mathrm{AC}$ concentration (B) Experimental conditions: see Fig.2.

As it can be seen from Fig. 3A, the best response corresponds to the variety of $A C$ obtained after chemical activation in $5 \% \mathrm{NaOH}$ solution; the others, activated more aggressively, had lower performances. It is possible that the porosity of the materials was affected by an aggressive treatment with concentrated $\mathrm{NaOH}$. Consequently, the variety activated with $\mathrm{NaOH} 5 \%$ was the one chosen for further experiments and comparisons.

As a second important parameter, the concentration of the AC containing suspension used for electrode surface modification was taken into consideration. Two different concentrations were considered: 0.011 $\mathrm{mg} / \mathrm{mL}$, used for SWCNT concentration in other studies [18] and a tenfold higher concentration of $0.11 \mathrm{mg} / \mathrm{mL}$. The concentration corresponding to the best electrochemical answer $(0.011 \mathrm{mg} / \mathrm{mL})$ (Figure 3B) was kept to prepare $\mathbf{G C / A C / N a f i o n ~ e l e c t r o d e s ~ u s e d ~ i n ~ f u r t h e r ~ e x p e r i m e n t s . ~}$

\section{CG electrodes modified with SWCNTs and RGO}

Aiming to select the most effective carbonaceous nanomaterial for the preparation of the modified GC electrodes, SWCNT and RGO were also used and their electrochemical response was recorded (Figs 4A and 5 A). Based on the SWAS voltammograms, calibration curves were plotted (Figs 4B and $5 \mathrm{~B}$ ) 


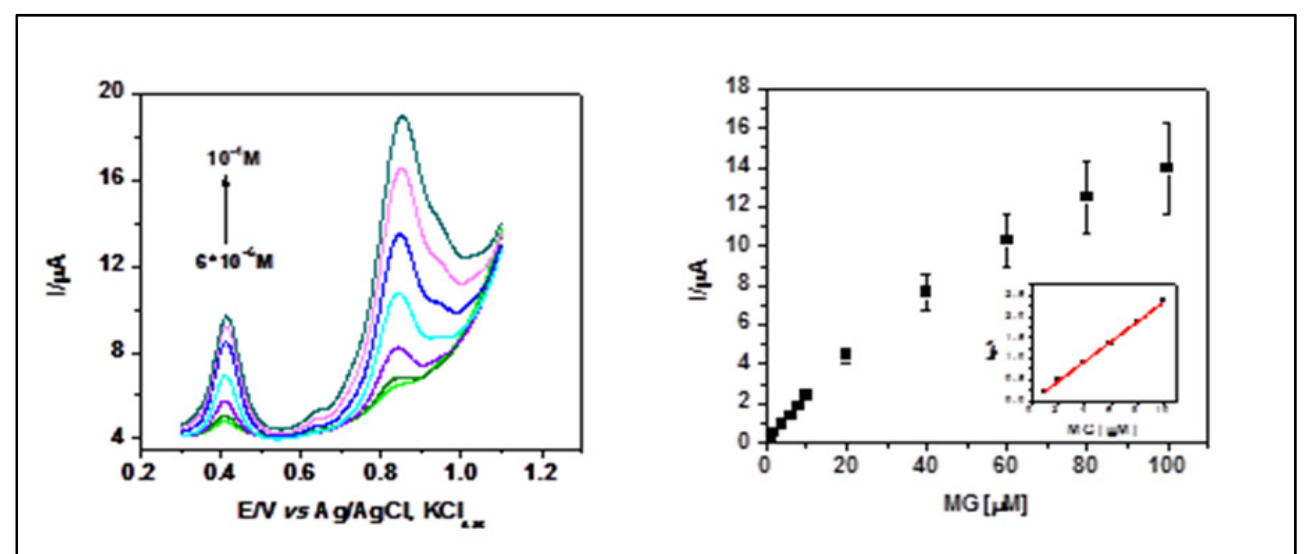

Figure 4. SWASV (A) and calibration curves (B) for GC/SWCNTs/Nafion electrode with linear part (inset in Fig 4B)). Experimental conditions: see Fig 2.

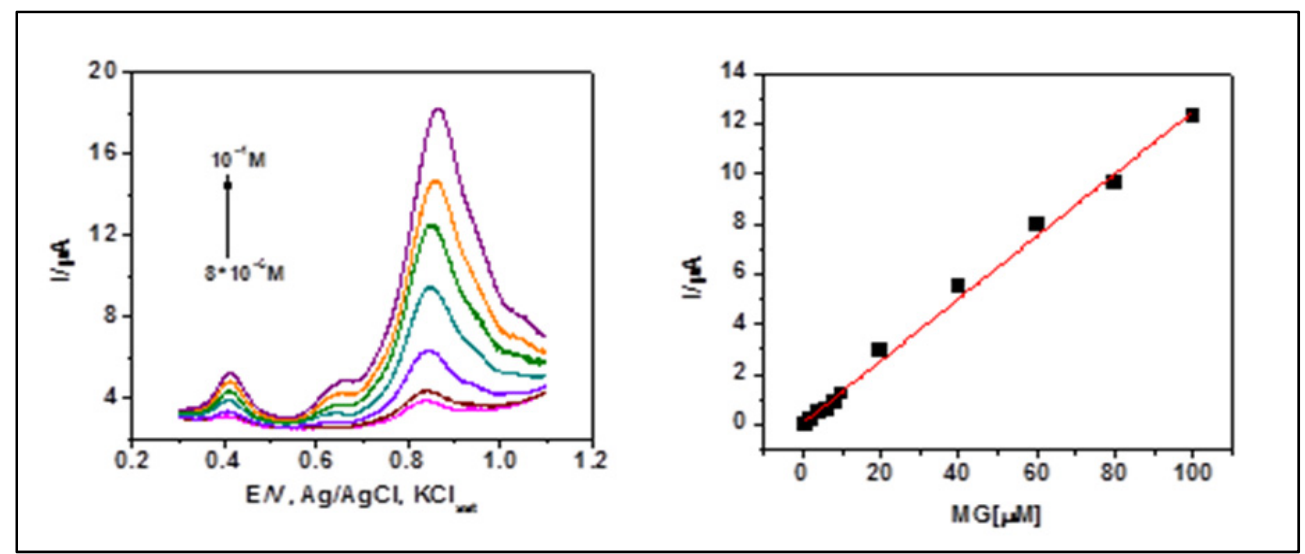

Figure 5. SWASV and calibration curves for GC/RGO/Nafion electrodes.

Experimental conditions: see Fig. 2.

The electrochemical parameters of the electrodes prepared with different carbonaceous materials $\left(E_{\text {peak }}\right.$ and $\left.I_{\text {peak }}\right)$ are given in Table 1. The values were taken from SWASV peak currents rendered for MG $10 \mu \mathrm{M}$.

Table 1. Electrochemical parameters of electrodes modified with carbonaceous materials. MG concentration, $10 \mu \mathrm{M}$.

\begin{tabular}{|c|c|c|}
\hline Electrode & $\mathbf{E}_{\text {peak }}(\mathbf{V})$ & $\mathbf{I}_{\text {peak }}(\boldsymbol{\mu} \mathbf{A})$ \\
\hline GC & 0.86 & 1.46 \\
\hline GC/Nafion & 0.89 & 1.10 \\
\hline GC/SWCNTs/Nafion & 0.84 & 2.37 \\
\hline GC/RGO/Nafion & 0.84 & 1.21 \\
\hline GC/AC/Nafion & 0.85 & 3.71 \\
\hline
\end{tabular}


It can be observed that both GC/SWCNTs/Nafion and GC/RGO/Nafion electrodes exhibit excellent catalytic activity toward MG oxidation, put in evidence by the increase of the peak current and a slight shift of the oxidation peak potentials toward more negative values. A direct comparison between the three carbonaceous materials is presented in Figure 6 , by means of the corresponding calibration curves.

The electroanalytical parameters presented in Table 2 point out to the fact that the electrodes prepared with SWCNT and AC exhibit best sensitivities and lowest detection limits. This suggests that these nanomaterials ensure best conductivity and active surface area to the modified electrodes.

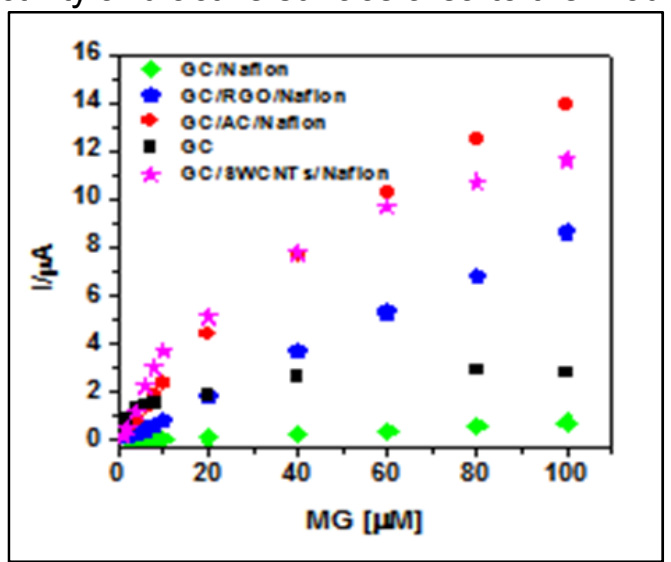

Figure 6. Calibration curves obtained for GC, GC/SWCNTs, GC/RGO and GC/AC electrodes, with Nafion coating, in SWASV.

Table 2. Electroanalytical parameters obtained for GC/Nafion, GC/SWCNTs/Nafion, GC/RGO/Nafion and GC/AC/Nafion electrodes' from SWASV calibration curves

\begin{tabular}{|c|c|c|c|c|}
\hline & GC/Nafion & $\begin{array}{c}\text { GC/SWCNTs/ } \\
\text { Nafion }\end{array}$ & $\begin{array}{c}\text { GC/RGO/ } \\
\text { Nafion }\end{array}$ & $\begin{array}{c}\text { GC/AC/ } \\
\text { Nafion }\end{array}$ \\
\hline Sensitivity (A/M) & $0.008 \pm 0.001$ & $0.236 \pm 0.003$ & $0.087 \pm 0.011$ & $0.403 \pm 0.013$ \\
\hline Linear domain $(\boldsymbol{\mu M})$ & $2-100$ & $1-10$ & $1-90$ & $1-10$ \\
\hline $\mathbf{D L}^{*}(\boldsymbol{\mu M})$ & 7.880 & 0.3308 & 3.9372 & 0.7763 \\
\hline $\mathbf{R}^{2} / \mathbf{n}$ & $0.9945 / 10$ & $0.999 / 6$ & $0.9986 / 10$ & $0.9945 / 6$ \\
\hline
\end{tabular}

* detection limit is calculated by formula $\mathrm{DL}=3{ }^{*} \mathrm{SD} /$ slope.

\section{Amperometry}

Amperometric analysis (Fig.7) was also carried out at GC/Nafion, GC/SWCNTs/Nafion, GC/RGO/Nafion and GC/AC/Nafion electrodes. The differences between the amperometric (Table 3) and SWASV results could 
be due to the absence of the accumulation step (300 s) used in SWASV measurements, which lead to lower detection limits in this method.
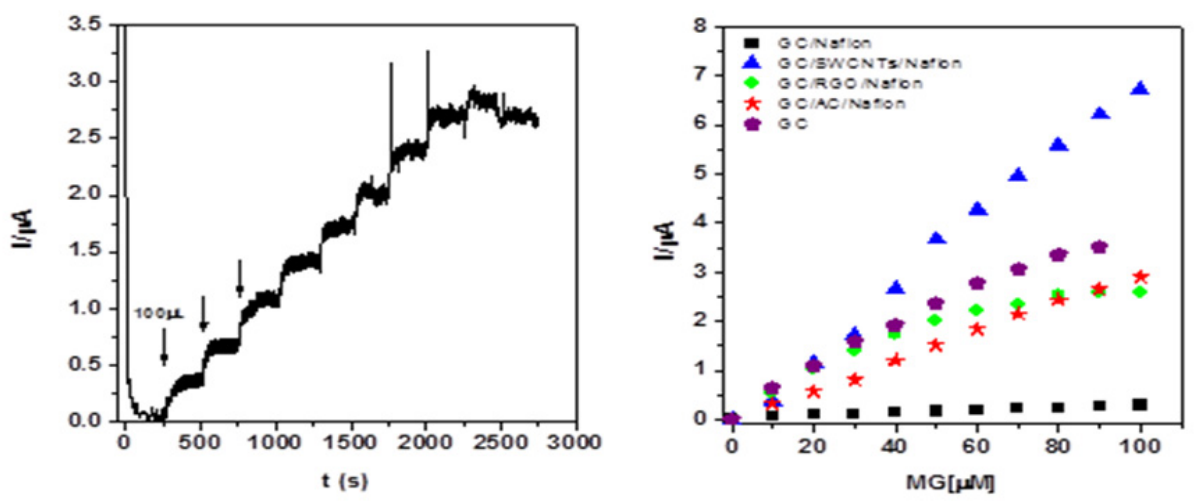

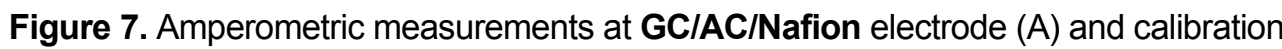
curves obtained for GC, GC/Nafion, GC/SWCNTs/Nafion, GC/RGO/Nafion and GC/AC/Nafion electrodes (B). Experimental conditions: PB solution, $\mathrm{pH}$ 3, working potential $0.85 \mathrm{~V} v$ s. $\mathrm{Ag} / \mathrm{AgCl} / \mathrm{KCl}_{\text {sat. }}$

As expected, the analytical parameters extracted from the amperometric calibration curves (Table 3 ) show the best performances of the electrodes modified with SWCNTs, but GC/AC/Nafion has also convenient characteristics. For all tested electrodes, the DL values are lower than those stipulated in the European legislation, (maximum allowed concentration of dyes in wastewater is $3.2^{*} 10^{-5} \mathrm{M}$ ) [19]

Table 3. Electroanalytical parameters obtained for GC/SWCNTs/Nafion,

GC/RGO/Nafion and GC/AC/Nafion electrodes

\begin{tabular}{|c|c|c|c|c|}
\hline & GC/Nafion & $\begin{array}{c}\text { GC/SWCNT/ } \\
\text { Nafion }\end{array}$ & $\begin{array}{c}\text { GC/RGO/ } \\
\text { Nafion }\end{array}$ & $\begin{array}{c}\text { GC/AC/ } \\
\text { Nafion }\end{array}$ \\
\hline $\begin{array}{c}\text { Sensitivity } \\
(\mathbf{A} / \mathbf{M})\end{array}$ & $0.0026 \pm 0.0001$ & $0.069 \pm 0.001$ & $0.046 \pm 0.001$ & $0.0233 \pm 0.0006$ \\
\hline $\begin{array}{c}\text { Linear domain } \\
(\boldsymbol{\mu M})\end{array}$ & $0-100$ & $0-100$ & $0-40 \mu \mathrm{M}$ & $0-100 \mu \mathrm{M}$ \\
\hline $\mathbf{D L}^{*}(\boldsymbol{\mu M})$ & 13.355 & 3.724 & 5.655 & 8.838 \\
\hline $\mathbf{R}^{\boldsymbol{\alpha}} / \mathbf{n}$ & $0.9841 / 11$ & $0.9978 / 11$ & $0.9953 / 5$ & $0.9929 / 1$ \\
\hline
\end{tabular}

* detection limit is calculated by formula $\mathrm{DL}=3^{*} \mathrm{SD} /$ slope.

\section{Electrochemical impedance spectroscopy}

To assess the activity of GC/SWCNTs/Nafion, GC/RGO/Nafion and GC/AC/Nafion modified electrodes, the $\left[\mathrm{Fe}(\mathrm{CN})_{6}\right]^{4-} \beta^{3-}$ couple $\left(10^{-3} \mathrm{M}\right.$ in $0.1 \mathrm{M}$ $\mathrm{KCl}$ solution) was employed as a redox probe in electrochemical impedance 
spectroscopy measurements. Fig. 8 shows the Nyquist plots corresponding to different modification of the GC electrode surface. It can be seen that the investigated electrodes exhibit a capacitive behavior at all frequencies.

The GC/Nafion electrode has the highest impedance when compared to the other electrodes, suggesting a more difficult electron transfer due to the polymeric coating that acts as a physical barrier. On the other hand, the negatively charged Nafion layer deposited on GC surface increases the bare electrode impedance by electrostatic rejection of the negative $\left[\mathrm{Fe}(\mathrm{CN})_{6}\right]^{4-} \beta^{3-}$ couple.

As expected, when carbonaceous materials are embedded in Nafion, the impedance decreases visibly due to the enhanced conductivity of the modified surface. The smallest impedance corresponds to the GC/SWCNTs/Nafion electrode, which exhibit also the largest surface area. The EIS results are thus in agreement with SWASV measurements.

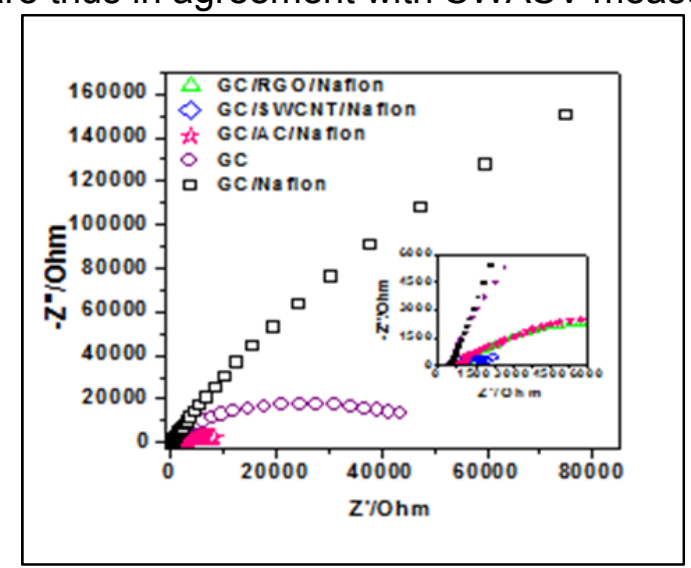

Figure 8. Electrochemical impedance spectroscopy at GC, GC/Nafion, GC/SWCNTs/Nafion, GC/RGO/Nafion and GC/AC/Nafion electrodes.

\section{Repeatability and stability}

Electrodes' stability was determined by cyclic voltammetry in MG solution simulating operational conditions. The modified electrodes were tested for 50 cycles in the working potential range $(0.3-1.1 \mathrm{~V})$, at $50 \mathrm{mV} / \mathrm{s}$ scan rate, in $100 \mu \mathrm{M}$ MG. The peak current decreased visibly for the first 10 cycles until a proper stabilization was established, being followed by steady currents further on. This behavior was similar for all tested electrodes. The stability after 50 cycles, taking cycle 10 as reference, was found to be 96.21 $\pm 0.07 \%$ for GC/SWCNTs/Nafion and $91.23 \pm 0.37 \%$ for GC/RGO/Nafion. The working stability for GC/AC/Nafion was a bit lower, $85.78 \pm 0.07 \%$, but the stability in buffer was comparable, $90.71 \%$. 
Repeatability of the measurements was calculated from peak current values obtained in SWASV for two or three different electrodes of each type, at a concentration of MG corresponding to the middle of the linear range of the calibration curves for each electrode. The values obtained for GC/SWCNTs/Nafion were RSD $=3.99 \%$ with a mean of 1.372 $\mu \mathrm{A}$ at $6 \mu \mathrm{M}$ MG for 3 measurements; for $\mathbf{G C} / \mathbf{R G O} /$ Nafion RSD $=5.80 \%$ with a mean of $1.913 \mu \mathrm{A}$ at $10 \mu \mathrm{M} \mathrm{MG}$ (and $1.42 \%$ with a mean of $1.549 \mu \mathrm{A}$ at $6 \mu \mathrm{M} \mathrm{MG}$ ) for 2 measurements; and for GC/AC/Nafion RSD $=0.44 \%$ with a mean of $2.24 \mu \mathrm{A}$ at $6 \mu \mathrm{M}$ MG for 2 measurements.

\section{CONCLUSIONS}

- A simple and sensitive electrochemical method was developed for the determination of MG in aqueous solutions.

- The MG oxidation peak current in SWASV is proportional to its concentration over a large range at all tested electrodes.

- All carbonaceous materials have a beneficial effect on the GC electrode, making it more sensitive and decreasing the detection limit due to the enhanced active surface and conductivity.

- SWCNTs have proven to be an excellent material for developing sensitive sensors, rendering the best results in SWASV and amperometry, with low detection limits.

- New artisanal AC has not reached the performances of SWCNTs, however it is comparable to commercial RGO, but much more costeffective.

- Carbonaceous nanomaterials have demonstrated their ability to be good auxiliary materials for modified electrodes in detecting large organic molecules like dyes.

\section{EXPERIMENTAL SECTION}

\section{CHEMICALS}

All the chemicals used were analytical grade, used as received, without further purification. Phosphate buffer solution was made from $\mathrm{NaH}_{2} \mathrm{PO}_{4}{ }^{*} \mathrm{H}_{2} \mathrm{O}$ and $\mathrm{Na}_{2} \mathrm{HPO}_{4}$ salts and $\mathrm{pH}$ corrected with $0-\mathrm{H}_{3} \mathrm{PO}_{4}$ acid from Merck, Germany. Malachite Green oxalate salt was purchased from Penta, Czech Republic. MG solutions were made in phosphate buffer $0.1 \mathrm{M}$. Sodium dodecyl sulphate (SDS) was acquired from Sigma, Switzerland. Nafion (perflourinated 5\% alcoholic solution from Aldrich, Belgium) was diluted using pure ethanol to obtain lower concentrations.

Single-walled carbon nanotubes (SWCNTs) were obtained from Aldrich, USA and reduced graphene oxide (RGO) from Graphenea, Spain. 


\section{PREPARATION OF ACTIVATED CARBON}

The activated carbon was obtained from Abies nordmanniana fir cone biomass [20] by chemical and physical activation. The fraction size chosen for treatment was $(0.2-0.4 \mathrm{~mm})$. Firstly, the fir cone biomass was mixed with a $\mathrm{NaOH}$ solution and left $72 \mathrm{~h}$ for activation. Three different concentrations $(5 \%$, $10 \%, 20 \%$ ) were tried to find an optimum. Thorough washing was needed to reach a neutral $\mathrm{pH}$. Subsequently, physical activation in $\mathrm{Ar}$ at $750^{\circ} \mathrm{C}$ for $2 \mathrm{~h}$ took place, resulting in a finely granulated activated carbon.

\section{PREPARATION OF THE MODIFIED ELECTRODE}

First and foremost, the GC electrode was cleaned thoroughly by polishing on felt with alumina slurry until mirror-like shine was obtained. Further cleaning was realized in acetone and distilled water in an ultrasound bath to remove any traces of MG or impurities.

The working electrode was modified with single-walled carbon nanotubes (SWCNT), reduced graphene oxide (RGO) or activated carbon (AC). Suspensions in $1 \%$ sodium dodecyl sulphate (SDS) were made with all three materials in the same concentration of $0.011 \mathrm{mg} / \mathrm{mL}$, which were applied by drop-casting and dried. A Nafion protective membrane was formed by evaporating $5 \mu \mathrm{L} 0.5 \%$ Nafion alcoholic solution.

\section{ELECTROCHEMICAL MEASUREMENTS}

All electrochemical experiments were performed on a Metrohm Autolab PGSTAT 302N, electrochemical workstation (Eco Chemie, Netherlands). A three-electrode system was used, equipped with a $\mathrm{Ag} / \mathrm{AgCl}, \mathrm{KCl}$ sat electrode as reference, a platinum wire as counter-electrode and a bare (or modified) glassy carbon (GC) electrode as the working electrode. The electrolyte solution was $0.1 \mathrm{M}$ phosphate buffer, $\mathrm{pH} 3$ adjusted with phosphoric acid. All experiments were performed at an ambient temperature of $25^{\circ} \mathrm{C}$.

Square wave anodic stripping voltammetry (SWASV)

Square wave anodic stripping voltammetry experiments were performed in phosphate buffer solutions with various concentrations of MG. The potential was varied from $0.3 \mathrm{~V}$ to $1.1 \mathrm{~V}$, at a frequency of $25 \mathrm{~Hz}$. Deposition time was established to be optimal at 300s, in open circuit, with 5 s equilibration time before each measurement.

\section{Amperometry}

Batch amperometry was employed as a second method for measuring MG concentrations in aqueous solutions. Additions of $100 \mu \mathrm{L}$ MG stock 
solution were made every precise number of seconds, under agitation at $200 \mathrm{rpm}$ in a $10 \mathrm{~mL}$ cell. The working potential was fixed at $0.85 \mathrm{~V}$ vs. $\mathrm{Ag} / \mathrm{AgCl} / \mathrm{KCl}_{\text {sat, }}$, value where MG peaks are very well contoured in SWASV voltammograms.

Electrochemical Impedance Spectroscopy

EIS experiments were performed in $0.1 \mathrm{~mol}^{-1} \mathrm{~L}^{-1} \mathrm{KCl}$ solution containing $1 \mathrm{mM} \mathrm{Fe}(\mathrm{CN})^{3-} / \mathrm{Fe}(\mathrm{CN})^{4-}$ at open circuit potential $(\mathrm{OCP})$, in a frequency domain of $10^{-2}-10^{5} \mathrm{~Hz}$.

\section{ACKNOWLEDGMENTS}

This work was supported by European Social Fund under the Human Resource Development Sectorial Operational Program 2007-2013, according to the $1^{\text {st }}$ Priority axes, project title "Quality, excellence and mobility in transnational doctoral research" POSDRU/187/1.5/S/155383.

The authors thank Dr. Gabriel Katona from the Faculty of Chemistry and Chemical Engineering for TEM analysis.

\section{REFERENCES}

1. F. Chequer, G. Rodrigues de Oliveira, E. Ferraz, J. Cardoso, M. Zanoni, D. Palma de Oliveira, "Eco-Friendly Textile Dyeing and Finishing", 2013, InTech.

2. G. Booth, "Dyes, General Survey", 2000, Wiley-VCH.

3. M.T. Yagub, T.K. Sen, S. Afroze, H.M. Ang, Advances in Colloid and Interface Science, 2014, 209: 172-184.

4. A. Hazrat, Water, Air, \& Soil Pollution, 2010, 213(1), 251.

5. P. Saravanan, P. Sivakumar, T. Suganya, N Nagendra, S. Renganathan, Indian Journal of Environmental Protection, 2012, 32(3): 249.

6. Y. Sun, Y. Yin, J. Zhang, H. Yu, X. Wang, Environmental Toxicology, 2006, 21(12): 256.

7. E. Daneshvar, M. Kousha, N. Koutahzadeh, M. Sohrabi, A. Bhatnagar, Environmental Progress \& Sustainable Energy, 2013, 32(2), 285.

8. A. Panandiker, C. Fernandes, K.Rao, Cancer Letters, 1992, 67, 93.

9. S. Srivastava, R. Sinha, D. Roy, Aquatic Toxicology, 2004, 66, 319.

10. G. Crini, Bioresource Technology, 2006, 97(9), 1061-86.

11. F.H. Wu, G.C. Zhao, X.W. Wei, Electrochemistry Communications, 2002, 4, 690.

12. L.M. Ochiai, D. Agustini, L. Figueiredo-Filho, C.E. Banks, L.H. MarcolinoJunior, M.F. Bergamini, Sensors and Actuators B, 2017, 241: 978.

13. M. Zhou, Y. Zhai, S. Dong, Analytical Chemistry, 2009, 81, 5603. 
14. H. Liu, K. Guo, C. Duan, X. Dong, J. Gao, Biosensors and Bioelectronics, 2017, 87, 473.

15. M. Mijanur-Rahman, M. Mollah, M. Muhibur-Rahman, A. Hasan-Susan, Hindawi Publishing Corporation, 2013, Article ID 839498; doi.org/10.1155/2013/839498.

16. Z. Galus, R. N. Adams, Journal of the American Chemical Society, 1964, 86, 1666.

17. A.M. Sacara, C. Cristea, L.M. Muresan, Journal of Electroanalytical Chemistry, 2017, 792, 23.

18. G.I. Turdean, G. Szabo, Food Chemistry, 2015, 179, 325.

19. ec.europa.eu/DocsRoom/documents/19163/attachments/1/...pdf viewed in June, 2017

20. A.M. Săcară, C. Indolean, L.M. Mureşan, Studia UBB Chemia, 2016, 61 (3), 183. 